\title{
Different ventilation modes combined with ambroxol in the treatment of respiratory distress syndrome in premature infants
}

\author{
BIN ZHOU $^{1}$, JING-FANG ZHAI ${ }^{2}$, JIE-BIN WU ${ }^{1}$, BAO JIN $^{1}$ and YAN-YAN ZHANG ${ }^{1}$ \\ Divisions of ${ }^{1}$ Pediatrics and ${ }^{2}$ Obstetrics, Xuzhou Central Hospital, The Affiliated Xuzhou Hospital of Medical College \\ of Southeast University; The Affiliated Xuzhou Center Hospital of Nanjing University of Chinese Medicine, \\ Xuzhou Clinical School of Xuzhou Medical College, Xuzhou, Jiangsu 221009, P.R. China
}

Received June 16, 2015; Accepted December 30, 2015

DOI: $10.3892 / \mathrm{etm} .2016 .3978$

\begin{abstract}
The aim of the present study was to compare the effectiveness of different modes of mechanical ventilation in combination with secretolytic therapy with ambroxol in premature infants with respiratory distress syndrome. Seventy-three premature infants with hyaline membrane disease (HMD) (stage III-IV), also known as respiratory distress syndrome, who were supported by mechanical ventilation in the neonatal intensive care unit (NICU) of Xuzhou Central Hospital, were involved in the present study, between January 2013 and February 2015. Forty cases were randomly selected and treated with high frequency oscillatory ventilation (HFOV), forming the HFOV group, whereas 33 cases were selected and treated with conventional mechanical ventilation (CMV), forming the CMV group. Patients in the two groups were administered ambroxol intravenously at a dosage rate of $30 \mathrm{mg} / \mathrm{kg}$ body weight at the beginning of the study. The present study involved monitoring the blood gas index as well as changes in the respiratory function index in the two groups. Additionally, the incidence of complications in the premature infants in the two groups was observed prior to and following the ventilation. Pulmonary arterial oxygen tension $\left(\mathrm{PaO}_{2}\right)$, the $\mathrm{PaO}_{2}$ /fraction of inspired oxygen $\left(\mathrm{FiO}_{2}\right)$ ratio, the oxygenation index $\left[\mathrm{OI}=100 \mathrm{x}\right.$ mean airway pressure $\left.(\mathrm{MAP}) \times \mathrm{FiO}_{2} / \mathrm{PaO}_{2}\right]$, as well as the arterial/alveolar oxygen partial pressure ratio $\left(\mathrm{a} / \mathrm{APO}_{2}\right)=\mathrm{PaO}_{2} /\left(713 \times \mathrm{FiO}_{2}\right.$ partial pressure of carbon dioxide $\left.\left(\mathrm{PaCO}_{2}\right) / 0.8\right)$ of the patients in the HFOV group after 1,12 and $24 \mathrm{~h}$ of treatment were significantly improved as compared to the patients of the CMV group. However, there was no significant difference between patients in the two groups with regard to the number of mortalities, complications such as pneumothorax, bronchopulmonary dysplasia (BPD),
\end{abstract}

Correspondence to: Dr Jie-Bin Wu, Division of Pediatrics, Xuzhou Central Hospital, 199 Jiefang Road, Xuzhou, Jiangsu 221009, P.R. China

E-mail: ranbow8459@126.com

Key words: ambroxol, respiratory distress syndrome retinopathy of prematurity (ROP), intraventricular hemorrhage (IVH), periventricular leukomalacia (PVL), and the time of ventilation. In conclusion, combining HFOV with ambroxol secretolytic therapy is a more viable option, as the combined treatment resulted in significant improvements in arterial blood gas levels, oxygenation and the respiratory function of lungs in preterm infants.

\section{Introduction}

Infant respiratory distress syndrome (IRDS) is a leading cause of mortality in infants, affecting $\sim 1 \%$ of newborn infants (1). Preterm babies with this condition are unable to adequately produce surfactant in the lungs due to the structural immaturity of their lungs. Surfactant is produced after $\sim 30-32$ weeks gestation, and thus preterm babies born prior to 30 weeks gestation are likely to develop IRDS (2). The prime reason for IRDS is developmental insufficiency, and in many cases it is caused by a genetic problem with lung development.

The management of IRDS involves the use of artificial respiratory support along with surfactant administration (3). Previous findings have confirmed the efficacy of these treatments in reducing mortality as well as morbidity caused by IRDS (4-6). Ambroxol is a secretolytic agent that was used in the present study. It is a mucoactive drug that stimulates the synthesis as well as the release of surfactants by type II pneumocytes (7). In physiological terms, surfactants reduce the adhesion of mucus to the bronchial wall, and improve its transport and provide protection against infections and irritating agents. On the other hand, artificial respiratory support in the form of mechanical ventilation aims to treat the hypoxaemia and hypercarbia associated with respiratory distress syndrome while minimising ventilator-associated lung trauma and oxygen toxicity (7).

Conventional mechanical ventilation (CMV) involved the delivery of a fixed number of breaths per minute via positive pressure ventilation, regardless of the baby's inspiratory effort $(2,8)$. It is associated with various side effects, including injury to the airways and lung parenchyma due to its invasive nature (9). These side effects led to the invention of modern mechanical ventilation methods including high frequency oscillatory ventilation (HFOV), which can be set to trigger or to coincide with the baby's inspiratory efforts $(10,11)$. Recent 
Table I. Comparison of the general clinical data of the premature infants in the two groups.

\begin{tabular}{|c|c|c|c|c|c|c|c|c|c|}
\hline \multirow[b]{2}{*}{ Groups } & \multirow[b]{2}{*}{ Cases } & \multirow{2}{*}{$\begin{array}{c}\text { Male/ } \\
\text { female } \\
\text { (n) }\end{array}$} & \multicolumn{2}{|c|}{ Apgar scores } & \multirow{2}{*}{$\begin{array}{c}\text { Infant age } \\
\text { (means } \pm \text { SD } \\
\text { weeks) }\end{array}$} & \multirow{2}{*}{$\begin{array}{l}\text { Birth body mass } \\
\text { (means } \pm \text { SD kg) }\end{array}$} & \multirow{2}{*}{$\begin{array}{l}\text { Length of } \\
\text { ventilation } \\
\text { (hours) }\end{array}$} & \multirow{2}{*}{$\begin{array}{c}\text { Prenatal } \\
\text { hormone } \\
\text { usage, n }(\%)\end{array}$} & \multirow{2}{*}{$\begin{array}{c}\text { PS usage } \\
\mathrm{n}(\%)\end{array}$} \\
\hline & & & $1 \mathrm{~min}$ & $5 \min$ & & & & & \\
\hline CMV group & 33 & $23 / 10$ & $5.27 \pm 1.61$ & $7.87 \pm 2.17$ & $32.35 \pm 1.95$ & $1.67 \pm 0.42$ & $4.23 \pm 2.12$ & $16(48.48)$ & $19(57.58)$ \\
\hline HFOV group & 40 & $26 / 14$ & $5.76 \pm 1.75$ & $7.66 \pm 1.84$ & $33.13 \pm 2.04$ & $1.73 \pm 0.49$ & $3.65 \pm 2.03$ & $23(57.50)$ & $26(65.00)$ \\
\hline T- or $\chi^{2}$ value & & 0.181 & 1.234 & 0.448 & 1.658 & 0.555 & 1.191 & 0.591 & 0.422 \\
\hline P-value & & $>0.05$ & $>0.05$ & $>0.05$ & $>0.05$ & $>0.05$ & $>0.05$ & $>0.05$ & $>0.05$ \\
\hline
\end{tabular}

CMV, conventional mechanical ventilation; HFOV, high frequency oscillatory ventilation; PS, pulmonary surfactant.

studies have confirmed the efficacy of modern ventilators as compared to conventional ventilators $(12,13)$. However, there is a paucity of information with regard to comparative analyses of these two modes when combined with surfactant therapy. Therefore, in the present study we compared the effects of CMV and HFOV when both are combined with secretolytic therapy (ambroxol) on respiratory distress syndrome in premature infants.

\section{Materials and methods}

Study population. All the cases were randomly selected according to the following criteria: i) babies were aged between 30 and 33 weeks old; and ii) babies had undergone artificial respiratory support procedures along with surfactant therapy during the time period spanning January 2013 to February 2015. Forty cases were randomly selected for the HFOV group, and 33 cases formed the CMV group. Apgarscores and prenatal hormone usage data for all cases were recorded. Secretolytic therapy with ambroxol, at a dose rate of $30 \mathrm{mg} / \mathrm{kg}$ body weight, was administered to infants in the two groups. Apgar scores as well as prenatal hormone usage (\%) were also recorded. Ethics approval for the study and research protocol was obtained from the Ethics Committee of Xuzhou Central Hospital (Xuzhou, China). The parents/guardians of all the participants provided written informed consent.

Application of the ventilator. Patients in the CMV group were treated using the mechanical ventilation mode of a Fabian neonatal/pediatric ventilator or Dräger Babylog 8000: synchronized intermittent mandatory ventilation (SIMV)-pressure control (PC) was used. Initial tuning parameters were: fraction of inspired oxygen $\left(\mathrm{FiO}_{2}\right)$ 0.4-0.6, peak inspiratory pressure (PIP) $15-20 \mathrm{~cm} \mathrm{H}_{2} \mathrm{O}\left(1 \mathrm{~cm} \mathrm{H} \mathrm{H}_{2} \mathrm{O}\right.$, $0.0981 \mathrm{kPa}$ ), positive end expiratory pressure (PEEP) $4-6 \mathrm{~cm}$ $\mathrm{H}_{2} \mathrm{O}$, breathing rate 40-50 times/min, and inspiratory duration 0.3-0.5 sec (by flow trigger). Inhalation of $\mathrm{FiO}_{2}$ was regulated to target peripheral capillary oxygen saturation $\left(\mathrm{SpO}_{2}\right)(88-93 \%)$ or pulmonary arterial oxygen tension $\left(\mathrm{PaO}_{2}\right)$ at $50-70 \mathrm{mmHg}(1 \mathrm{mmHg}, 0.133 \mathrm{kPa})$, and PIP as well as the respiratory rate were adjusted to maintain the tidal volume between 4 and $6 \mathrm{ml} / \mathrm{kg}$ and the partial pressure of carbon dioxide $\left(\mathrm{PaCO}_{2}\right)$ at $35-50 \mathrm{mmHg}$. The parameters of the ventilator were adjusted according to blood gas levels and $\mathrm{SpO}_{2}$. However, after the infant's condition improved, the parameters were reduced to $\mathrm{FiO}_{2} \leq 0.35$, PIP $\leq 10 \mathrm{~cm} \mathrm{H}_{2} \mathrm{O}$, PEEP $\leq 3 \mathrm{~cm} \mathrm{H}_{2} \mathrm{O}$.

Patients in the HFOV group were treated with a Fabian neonatal high-frequency ventilator, with the initial $\mathrm{FiO}_{2}$ at 0.5-0.8 and frequency at 9-12 Hz. The mean airway pressure (MAP) was adjusted to the arterial $\mathrm{CO}_{2}$ tension level, although 11-13 $\mathrm{cm} \mathrm{H}_{2} \mathrm{O}$ was initially used prior to an increase every 10-15 min. $\mathrm{FiO}_{2}$ was adjusted via $\mathrm{SpO}_{2}$ monitoring, until oxygenation was increased. The target blood gas values were maintained as follows: $\mathrm{PaO}_{2}, 50-70 \mathrm{mmHg}$ and $\mathrm{PaCO}_{2}$, $35-50 \mathrm{mmHg}$. After the condition improved, the parameters for $\mathrm{FiO}_{2}$ and MAP were reduced.

Secretolytic therapy. The two groups were administered secretolytic therapy in the form of bovine pulmonary surfactant (PS) (Beijing Double-Crane Modern Pharmaceutical Technology Co., Ltd., Beijing, China). The first dose consisted of $70 \mathrm{mg} / \mathrm{kg}$, and was administered according to the manufacturer's instructions. Administration was repeated 1-3 times, dosing intervals were every $6-12 \mathrm{~h}$ and the majority of patients were administered therapy 3 times. The method of administration was via an aseptic nasal feeding tube. Endotracheal intubation was extended to the edge of the intubation with the assistance of endotracheal instillation. The total duration of the therapy was 7 days.

Statistical analysis. SPSS 19 software (IBM Corp., Armonk, NY, USA) was used to perform statistical analysis. The data were presented as the means \pm SD. The Student's t-test was used for comparisons between the groups. Count data were expressed as percentages. The $\chi^{2}$ test was used to test significant association (if any) between the variables. $\mathrm{P}<0.05$ indicated a statistically significant difference.

\section{Results}

A total of 73 cases were randomly divided into two groups on the basis of the type of mechanical ventilation used. Thirty-three infants with average ages of $32.35 \pm 1.95$ weeks were given CMV. The remaining 40 infants, average ages of $33.13 \pm 2.04$ weeks, were treated with HFOV. The two groups were treated with secretolytic therapy with ambroxol. The differences in the general clinical indices (Table I) of the two groups were not statistically significant, thus confirming the uniformity of the present study. Additionally, Apgar scores 
Table II. Changes to arterial blood gas indices of premature infants with HMD treated with different ventilation modes, at various time-points.

\begin{tabular}{|c|c|c|c|c|c|c|c|c|c|}
\hline \multirow[b]{2}{*}{ Groups } & \multirow[b]{2}{*}{ Cases } & \multicolumn{4}{|c|}{$\mathrm{pH}$} & \multicolumn{4}{|c|}{$\mathrm{PaO}_{2}(\mathrm{mmHg})$ arterial oxygen tension } \\
\hline & & $0 \mathrm{~h}$ & $1 \mathrm{~h}$ & $12 \mathrm{~h}$ & $24 \mathrm{~h}$ & $0 \mathrm{~h}$ & $1 \mathrm{~h}$ & $12 \mathrm{~h}$ & $24 \mathrm{~h}$ \\
\hline CMV group & 33 & $7.23 \pm 0.12$ & $7.30 \pm 0.08$ & $7.33 \pm 0.09$ & $7.37 \pm 0.11$ & $46.06 \pm 1.41$ & $55.87 \pm 3.82$ & $58.45 \pm 3.63$ & $62.64 \pm 4.52$ \\
\hline HFOV group & 40 & $7.21 \pm 0.15$ & $7.31 \pm 0.08$ & $7.34 \pm 0.07$ & $7.36 \pm 0.10$ & $46.14 \pm 1.76$ & $57.90 \pm 4.26$ & $61.44 \pm 4.03$ & $65.81 \pm 5.64$ \\
\hline T-value & & 0.619 & 0.532 & 0.534 & 0.406 & 0.211 & 2.122 & 3.298 & 2.610 \\
\hline \multirow[t]{2}{*}{ P-value } & & $>0.05$ & $>0.05$ & $>0.05$ & $>0.05$ & $>0.05$ & $<0.05$ & $<0.05$ & $<0.05$ \\
\hline & & \multicolumn{4}{|c|}{$\mathrm{PaCO}_{2}(\mathrm{mmHg})$} & \multicolumn{3}{|c|}{$\mathrm{PaO}_{2} / \mathrm{FiO}_{2}(\mathrm{mmHg})$} & \\
\hline Groups & Cases & $0 \mathrm{~h}$ & $1 \mathrm{~h}$ & $12 \mathrm{~h}$ & $24 \mathrm{~h}$ & $1 \mathrm{~h}$ & $12 \mathrm{~h}$ & $24 \mathrm{~h}$ & \\
\hline CMV group & 33 & $60.96 \pm 6.46$ & $57.25 \pm 4.56$ & $50.05 \pm 4.18$ & $44.96 \pm 3.97$ & $104.24 \pm 31.85$ & $110.08 \pm 26.09$ & $128.73 \pm 33.00$ & \\
\hline HFOV group & 40 & $61.42 \pm 6.80$ & $55.64 \pm 5.85$ & $51.19 \pm 3.42$ & $45.94 \pm 5.31$ & $120.41 \pm 30.84$ & $127.52 \pm 30.77$ & $145.54 \pm 34.59$ & \\
\hline T-value & & 0.294 & 1.290 & 1.282 & 0.877 & 2.197 & 2.579 & 2.110 & \\
\hline P-value & & $>0.05$ & $>0.05$ & $>0.05$ & $>0.05$ & $<0.05$ & $<0.05$ & $<0.05$ & \\
\hline
\end{tabular}

$\mathrm{HMD}$, hyaline membrane disease; $\mathrm{CMV}$, conventional mechanical ventilation; $\mathrm{HFOV}$, high frequency oscillatory ventilation; $\mathrm{PaCO}_{2}$, partial pressure of carbon dioxide; $\mathrm{PaO}_{2}$, pulmonary arterial oxygen tension; $\mathrm{FiO}_{2}$, fraction of inspired oxygen.

Table III. Changes to the arterial respiratory function index of premature infants with HMD treated with different ventilation modes, at various time-points.

\begin{tabular}{|c|c|c|c|c|c|c|c|}
\hline \multirow[b]{2}{*}{ Groups } & \multirow[b]{2}{*}{ Cases } & \multicolumn{3}{|c|}{$\mathrm{FiO}_{2}$} & \multicolumn{3}{|c|}{$\operatorname{MAP}\left(\mathrm{cm} \mathrm{H}_{2} \mathrm{O}\right)$} \\
\hline & & $1 \mathrm{~h}$ & $12 \mathrm{~h}$ & $24 \mathrm{~h}$ & $1 \mathrm{~h}$ & $12 \mathrm{~h}$ & $24 \mathrm{~h}$ \\
\hline CMV group & 33 & $0.59 \pm 0.17$ & $0.57 \pm 0.12$ & $0.53 \pm 0.11$ & $13.24 \pm 1.75$ & $13.12 \pm 1.90$ & $12.97 \pm 1.63$ \\
\hline HFOV group & 40 & $0.52 \pm 0.13$ & $0.50 \pm 0.10$ & $0.47 \pm 0.09$ & $13.48 \pm 1.57$ & $13.43 \pm 1.50$ & $13.15 \pm 1.42$ \\
\hline T-value & & 1.993 & 2.719 & 2.564 & 0.617 & 0.779 & 0.504 \\
\hline \multirow[t]{2}{*}{ P-value } & & $<0.05$ & $<0.05$ & $<0.05$ & $>0.05$ & $>0.05$ & $>0.05$ \\
\hline & & \multicolumn{3}{|c|}{ OI } & \multicolumn{3}{|c|}{$\mathrm{a} / \mathrm{APO}_{2}$} \\
\hline Groups & Cases & $1 \mathrm{~h}$ & $12 \mathrm{~h}$ & $24 \mathrm{~h}$ & $1 \mathrm{~h}$ & $12 \mathrm{~h}$ & $24 \mathrm{~h}$ \\
\hline CMV group & 33 & $17.70 \pm 7.49$ & $14.01 \pm 5.15$ & $12.18 \pm 5.01$ & $0.17 \pm 0.05$ & $0.19 \pm 0.06$ & $0.21 \pm 0.07$ \\
\hline HFOV group & 40 & $13.59 \pm 6.25$ & $11.54 \pm 4.52$ & $9.94 \pm 3.81$ & $0.20 \pm 0.07$ & $0.22 \pm 0.05$ & $0.25 \pm 0.06$ \\
\hline T-value & & 2.556 & 2.182 & 2.169 & 2.064 & 2.331 & 2.629 \\
\hline P-value & & $<0.05$ & $<0.05$ & $<0.05$ & $<0.05$ & $<0.05$ & $<0.05$ \\
\hline
\end{tabular}

$\mathrm{HMD}$, hyaline membrane disease; $\mathrm{CMV}$, conventional mechanical ventilation; $\mathrm{HFOV}$, high frequency oscillatory ventilation; $\mathrm{FiO}_{2}$, fraction of inspired oxygen; OI, oxygenation index; MAP, mean airway pressure; a/APO2; arterial/alveolar oxygen partial pressure ratio.

Table IV. Comparison of the outcomes and complications of preterm infants with HMD treated with different ventilation modes.

\begin{tabular}{|c|c|c|c|c|c|c|c|c|}
\hline Groups & Cases & $\begin{array}{c}\text { Cases } \\
\text { of death } \\
\mathrm{n}(\%)\end{array}$ & $\begin{array}{c}\text { Time of } \\
\text { ventilation } \\
\text { means } \pm \mathrm{SD}\end{array}$ & $\begin{array}{c}\text { Cases of } \\
\text { pneumothorax } \\
\mathrm{n}(\%)\end{array}$ & $\begin{array}{c}\text { Cases of } \\
\text { BPD } \\
\mathrm{n}(\%)\end{array}$ & $\begin{array}{c}\text { Cases of } \\
\text { ROP } \\
\text { n }(\%)\end{array}$ & $\begin{array}{c}\text { Cases of } \\
\text { IVH } \\
\mathrm{n}(\%)\end{array}$ & $\begin{array}{c}\text { Cases of } \\
\text { PVL } \\
\text { n }(\%)\end{array}$ \\
\hline CMV group & 33 & $3(9.09)$ & $3.77 \pm 1.03$ & $2(6.06)$ & $1(3.03)$ & $2(6.06)$ & $10(30.30)$ & $5(15.15)$ \\
\hline HFOV group & 40 & $2(5.00)$ & $3.62 \pm 1.14$ & $1(2.50)$ & $1(2.50)$ & $1(2.50)$ & $14(35.00)$ & $4(10.00)$ \\
\hline T-value & & 0.050 & 0.584 & 0.029 & 0.339 & 0.029 & 0.181 & 0.095 \\
\hline $\mathrm{P}$-value & & $>0.05$ & $>0.05$ & $>0.05$ & $>0.05$ & $>0.05$ & $>0.05$ & $>0.05$ \\
\hline
\end{tabular}

HMD, hyaline membrane disease; CMV, conventional mechanical ventilation; HFOV, high frequency oscillatory ventilation; BPD, bronchopulmonary dysplasia; ROP, retinopathy of prematurity; IVH, intraventricular hemorrhage; PVL, periventricular leukomalacia. 
and prenatal hormone usage (\%) did not show any statistically significant difference. On the other hand, a statistically significant improvement (Table II) was observed in the $\mathrm{PaO}_{2}$ of the HFOV group as compared to that of the CMV group after 1,2 and $12 \mathrm{~h}$ of treatment. In addition, $\mathrm{FiO}_{2}$ was significantly decreased (Table III) in the HFOV and CMV groups. Combined treatment led to a significant improvement in the $\mathrm{PaO}_{2} / \mathrm{FiO}_{2}$ ( $\mathrm{PF}$ ) ratio (Table II) of the lungs in the HFOV group as compared to the CMV group. Furthermore, no significant differences were recorded in $\mathrm{PaCO}_{2}$ or $\mathrm{pH}$ values (Table II) between the two groups.

In our evaluation of the oxygenation index (OI) in IVRD infants, a significant decrease (Table III) in the HFOV group in comparison with that of the CMV group was identified. Moreover, the arterial/alveolar oxygen tension ratio $\left(\mathrm{a} / \mathrm{APO}_{2}\right)$ ratios demonstrated a statistically significant increase (Table III) in the HFOV group as compared to the CMV group after each time interval of treatment. However, MAP values did not differ significantly between the two groups. As shown in Table IV, there were no significant differences between the groups with regard to complications such as motality, pneumothorax, bronchopulmonary dysplasia (BPD), retinopathy of prematurity (ROP), intraventricular hemorrhage (IVH) and periventricular leukomalacia (PVL).

\section{Discussion}

The present study compared the effectiveness of combined therapy comprising HFOV and secretolytic therapy (using ambroxol) to that comprising CMV and secretolytic therapy (using ambroxol) in premature infants with respiratory distress syndrome. The results clearly show the efficacy of HFOV over CMV in 73 premature infants. In the present study, we tested preterm infants in the two groups using the arterial blood gas (ABG) test. The ABG test is one of the most widely used tests in cases of respiratory distress syndrome, as it provides essential information concerning gas exchange across the alveolar-capillary membrane (14). It measures $\mathrm{PaO}_{2}, \mathrm{PaCO}_{2}$, and the $\mathrm{pH}$ of an arterial blood sample.

The $\mathrm{PaO}_{2}$ of infants in the HFOV group improved significantly as compared to that of the CMV group. Measuring $\mathrm{PaO}_{2}$ revealed the partial pressure of oxygen in the blood, which is significant, as it is directly associated with ventilation and oxygenation. In respiratory distress syndrome, oxygen tension is decreased by $\leq 50 \mathrm{~mm}$. In the present study, the treatment with $\mathrm{CMV}$ and ambroxol improved partial oxygen tension levels. The positive pressure delivered by CMV likely contributed to the observed increase in $\mathrm{PaO}_{2}$. Furthermore, the improvement in $\mathrm{PaO}_{2}$ was much greater in the HFOV group, and it increased to $>65 \mathrm{~mm}$. The reason for this improvement is that HFOV delivers extremely rapid rates ( $600-800$ breaths per min) of very small tidal volumes. Moreover, HFOV coincides with the patient's inspiratory efforts, which contributes to an increase in arterial oxygen tension, as has been previously noted (15).

This evaluation of respiratory function revealed that $\mathrm{FiO}_{2}$ levels were significantly decreased in the two groups following treatment with combination therapy. However, greater moderation was observed in the HFOV group. $\mathrm{FiO}_{2}$ values provide us with an estimate of oxygen involvement in gas exchange in alveoli. $\mathrm{FiO}_{2}$ values are crucial, as they directly affect the Carrico index (the $\mathrm{PaO}_{2} / \mathrm{FiO}_{2}$ ratio), which is the ratio of pulmonary arterial oxygen tension to the fraction of inspired oxygen (16). In other words, the Carrico index is useful in determining the ability of the lungs to transfer oxygen to the blood. Usually, the Carrico index is low in IRDS patients. In the present study, we observed a significant decrease in $\mathrm{FiO}_{2}$ values in the two groups of premature infants with IRDS and a significant improvement in the Carrico index of the two groups. However, the improvement was much greater in the HFOV group, due to a greater reduction in $\mathrm{FiO}_{2}$ caused by higher breathing rates, as compared to the CMV group.

The OI is another crucial parameter that provides us with information concerning $\mathrm{FiO}_{2}$ as well as $\mathrm{O}_{2}$ utilization. The lower the $\mathrm{OI}$ is, the better the physiological function of the lungs. The OI is directly proportional to $\mathrm{FiO}_{2}$ values and inversely proportional to $\mathrm{PaO}_{2}$ values. Thus, the decreased $\mathrm{FiO}_{2}$ values and elevated $\mathrm{PaO}_{2}$ following the combination treatment in the HFOV group resulted in a lower OI. Therefore, the marked decrease in the OI confirmed the effectiveness of HFOV over CMV. Addtionally, estimation of these indices allowed us to evaluate the a/APO $\mathrm{O}_{2}$ ratio, which was also significantly improved in the preterm babies of the HFOV group.

It can be concluded from the present study that HFOV is a more viable option than CMV when combined with secretolytic therapy using ambroxol to treat preterm babies with respiratory distress syndrome. This method may become the gold standard for preterm infants with respiratory distress syndrome in the future.

\section{Acknowledgements}

This study was supported by the Project of Xuzhou Technology Bureau (no. KC14SH025).

\section{References}

1. Rodriguez RJ, Martin RJ and Fanaroff AA: Respiratory distress syndrome and its management. In: Neonatal-Perinatal Medicine: Diseases of the Fetus and Infant. Fanaroff AA and Martin RJ (eds). Mosby, St. Louis, pp1001-1011, 2002.

2. Fraser J, Walls M and McGuire W: Respiratory complications of preterm birth. BMJ 329: 962-965, 2004.

3. Dani C, Ravasio R, Fioravanti L and Circelli M: Analysis of the cost-effectiveness of surfactant treatment (Curosurf ${ }^{\circledR}$ ) in respiratory distress syndrome therapy in preterm infants: early treatment compared to late treatment. Ital J Pediatr 40: 40, 2014.

4. Ho JJ, Henderson-Smart DJ and Davis PG: Early versus delayed initiation of continuous distending pressure for respiratory distress syndrome in preterm infants. Cochrane Database Syst Rev 2: CD002975, 2002.

5. Henderson-Smart DJ, Wilkinson A and Raynes-Greenow $\mathrm{CH}$ : Mechanical ventilation for newborn infants with respiratory failure due to pulmonary disease. Cochrane Database Syst Rev 4: CD002770, 2002.

6. Attar MA and Donn SM: Mechanisms of ventilator-induced lung injury in premature infants. Semin Neonatol 7: 353-360, 2002.

7. Gupta PR: Ambroxol - Resurgence of an old molecule as an antiinflammatory agent in chronic obstructive airway diseases. Lung India 27: 46-48, 2010.

8. Mechanical Ventilation Committee of the Brazilian Intensive Care Medicine Association; Commission of Intensive Therapy of the Brazilian Thoracic Society: Brazilian recommendations of mechanical ventilation 2013. Part I. J Bras Pneumol 40: 327-363, 2014 (In English and Portuguese). 
9. Marini JJ: Mechanical ventilation: past lessons and the near future. Crit Care 17 (Suppl 1): S1, 2013.

10. Mikusiakova LT, Pistekova H, Kosutova P, Mikolka P, Calkovska A and Mokra D: Effects on lung function of smallvolume conventional ventilation and high-frequency oscillatory ventilation in a model of meconium aspiration syndrome. Adv Exp Med Biol: May 28, 2015 (Epub ahead of print).

11. Niwa T, Hasegawa R, Ryuge M, Kawase M, Kondoh Y and Taniguchi H: Benefits and risks associated with the R100 high frequency oscillatory ventilator for patients with severe hypoxaemic respiratory failure. Anaesth Intensive Care 39: 1111-1119, 2011.

12. Ip T and Mehta S: The role of high-frequency oscillatory ventilation in the treatment of acute respiratory failure in adults. Curr Opin Crit Care 18: 70-79, 2012.
13. Naorungroj T, Vilaichone W, Tongyoo S, Thamrongpairoj P and Permpikul C: High-frequency oscillatory ventilation for patients during exudative phase of severe ARDS. J Med Assoc Thai 98: 343-351, 2015.

14. Blum FE, Lund ET, Hall HA, Tachauer AD, Chedrawy EG and Zilberstein J: Reevaluation of the utilization of arterial blood gas analysis in the Intensive Care Unit: effects on patient safety and patient outcome. J Crit Care 30: 438.e1-438.e5, 2015.

15. Chassery C, Bouchut JC, Blaise BJ, Courtil-Teyssedre S and Gueugniaud PY: Ventilation of severe bronchiolitis in interhospital transport: a place for high frequency oscillatory ventilation? Paediatr Anaesth 25: 643-644, 2015.

16. Kočan L, Vašková J, Vaško L, Simonová J, Simon R and Firment J: Selenium adjuvant therapy in septic patients selected according to Carrico index. Clin Biochem 47: 44-50, 2014. 